\title{
Towards a simulation-based understanding of smart remanufacturing operations: a comparative analysis
}

Check for updates

\section{Okechukwu Okorie $^{1}$ (D) Fiona Charnley ${ }^{1} \cdot$ Augustine Ehiagwina $^{2} \cdot$ Divya Tiwari $^{3} \cdot$ Konstantinos Salonitis ${ }^{4}$}

Received: 25 February 2020 / Accepted: 21 May 2020/Published online: 12 June 2020

(C) The Author(s) 2020

\begin{abstract}
While the majority of literature on remanufacturing operations examines an end-oflife (EOL) strategy which is both manual and mechanised, authors generally agree that digitalisation of remanufacturing is expected to increase in the next decade. Subsequently, a new research area described as digitally-enabled remanufacturing, remanufacturing 4.0 or smart remanufacturing is emerging. This is an automated, data-driven system of remanufacturing by means of Industry 4.0 (I4.0) paradigms. Insights into smart remanufacturing can be provided through simulation modelling of the remanufacturing process. While the use of simulation modelling in order to predict responses and behaviour is prevalent in remanufacturing, the use of these tools in smart remanufacturing is still limited in literature. The goal of this research is to present, as a first of its kind, a comparative understanding of simulation modelling in remanufacturing in order to suggest the ideal modelling tool for smart remanufacturing. The proposed comparison includes system dynamics, discrete event simulation and agent based modelling techniques. We apply these modelling techniques on a smart remanufacturing space of a sensor-enabled product and use assumptions derived from industry experts. We then proceed to model the remanufacturing operation from sorting and inspection of cores to final inspection of the remanufactured product. Through our analysis of the assumptions utilised and simulation modelling results we conclude that, while individual modelling techniques present important strategic and operational insights, their individual use may not be sufficient to offer comprehensive knowledge to remanufacturers due to the challenge of data complexity that smart remanufacturing offers.
\end{abstract}

Keywords Simulation modelling · Smart remanufacturing $\cdot$ System dynamics · Discrete event simulation $\cdot$ Agent-based simulation

Okechukwu Okorie

o.s.okorie@exeter.ac.uk

Extended author information available on the last page of the article 


\section{Introduction}

There is an acceptance by researchers, academics, manufacturers and policymakers of the urgent need to transition from a linear model, which extracts resources and manufactures them into products that are disposed after use, into a circular model [14, 44, 47]. The circular economy model is focused on value retention, where the resources are kept in use for as long as possible; hence it is restorative and regenerative by design and intention [12]. Circular economy research has motivated the emergence of a new supply chain paradigm, the closedloop supply chain [47]. Accordingly, these closed-loop supply chain (CLSC) systems include material recovery processes such as remanufacturing, recycling, repairing and reusing [17, 20].

Ponte et al., [47] reflects on the foregoing and concludes that remanufacturing has become one of the cornerstone of this emerging circular economy. There are several definitions of remanufacturing and these definitions has been deployed in literature with various meanings, sometimes creating ambiguity [2, 21, 55, 56]. However, in an early definition of remanufacturing. In an extended definition, Lund defines remanufacturing as "an industrial process in which worn-out products are restored to like-new condition through a series of industrial processes in a factory environment. The discarded product is completely disassembled, its useable parts are cleaned, reconditioned and put into inventory. Then the new product is reassembled from the old and, where necessary, new parts to produce a fully equivalent and sometimes superior in performance and expected lifetime to the original new product" [36, 37]. Currently (and beyond profitability), remanufacturing has been argued as part of the solution to reduce resource consumption while retaining economic advancement [58]. According to the Ellen MacArthur Foundation (EMF), it decouples economic growth from environmental impact [38]. Following this, several papers have emphasized the link between remanufacturing and sustainability $[18,50,51]$. The United Nations Environmental Programme (UNEP) International Resource Panel (IRP) on the circular economy makes this link evident, highlighting remanufacturing as one of the key circular approach needed to redefine value for a sustainable manufacturing. Thus, remanufacturing has been described as a value retention process, VRP [57].

Smart remanufacturing, however, is relatively new and emerging research area in literature. It has been described as in various terms such as remanufacturing 4.0 [7], I4.0 enabled remanufacturing [27,62] data-driven remanufacturing [45], digital remanufacturing [52] as well as smart remanufacturing [28, 63]. In their review studies on smart remanufacturing, Kerin and Pham [28] define smart remanufacturing as the utilization of I4.0 technologies on the product to be remanufactured as well as the remanufacturing processing equipment and business management systems. Thus, the application of I4.0 paradigms, (cyber-physical systems, cloud manufacturing, internet of things, additive manufacturing [25]) in remanufacturing operations can be broadly said to be smart remanufacturing. The emergence of this term has not been without its challenges. Kurilova-Palisaitiene and Sundin [30] had argued that the remanufacturing sector is even more complex than the manufacturing industry sector and hence, a blanket transfer of I4.0 paradigms to the remanufacturing industry sector will not be expedient [7]. It is also argued that an overarching definition must include a research agenda that extends into understanding the technological, business model, economic, social and environmental needs for smart remanufacturing [7]. This may also extend into smart remanufacturing factories $[15,63]$. What is generally accepted, however, is the potential for I4.0 to revolutionize remanufacturing as is the case with manufacturing [39]. 
Simulation modelling has been proposed in literature as a method in gaining insights of manufacturing and remanufacturing challenges, especially as regards to uncertainties. Primary tools used in manufacturing research includes System Dynamics (SD), Discrete Event Simulation (DES) and Agent Based Modelling (ABM) [13]. While there has been extended research in remanufacturing [35], research on enabling remanufacturing using simulation is still limited. Using the selected keywords of "simulat*" OR "modelling" AND "remanufact*" on SCOPUS, ${ }^{1} 56$ articles emerges when the keywords are restricted to article titles only. In contrast, Lee and Kwak [35] discovered 369 articles in remanufacturing in the International Journal of Production Economics alone, with most of the remanufacturing articles being studied in the field of "supply chain", "environmental" studies and "sustainability". Like traditional manufacturing, simulation modelling supports remanufacturing by providing insights into manufacturing and remanufacturing, predicting the shop-floor behaviour in order to support the remanufacturer in suggesting solutions from real-time analysis. As a process, remanufacturing is subject to a number of challenges and uncertainties such as price fluctuation, stochastic demand and challenges related to the core (used product or its part) such as uncertain quality of returned used products, timing and quality [32]. The European Remanufacturing Network (ERN) from its survey research on 188 European remanufacturers also highlights the lack of accurate, timely and consistent product knowledge challenge.

In their paper investigating simulation modelling in manufacturing Jahangirian et al., [24] concludes that these three techniques are the most widely used. While simulation modelling has verifiably extended into remanufacturing from manufacturing, we find no papers that comparatively investigates these three modelling approach for smart remanufacturing. New products such as sensor-enabled products and smart devices [22, 35] are expected to enter the remanufacturing stream as Original Equipment Manufacturers (OEMs) digitalise their operations and products. I4.0 adoption is also expected to increase in remanufacturing, with Kerin and Pham [27] as some of the researchers advancing the applicability of the Internet of Things (IoT), Virtual Reality (VR) and Augmented Reality (AR) in remanufacturing. Expectedly, data and information flow and complexity is expected to increase in remanufacturing. This study builds on our previous studies [22, 36, 37], by comparatively analysing the SD, DES and ABM simulation modelling as applied to smart remanufacturing operations. It therefore poses the research question: What advantages does the three core simulation modelling tools provide for the smart remanufacturing context? We expect an identification of this advantages to be important to remanufacturers and closed loop supply chain researchers. Hybrid modelling, where at least two of these three approaches are used to model complex enterprise-wide systems, have also grown over the years, however this is not within the scope of this research.

\section{Simulation modelling in remanufacturing}

While simulation modelling does not rank within the top 12 research topic areas in remanufacturing when a citation network analysis of remanufacturing articles from SCOPUS is performed, "simulation" was found to be a keyword across the analysis of approximately 7300 articles [35]. In a survey of the use of simulation in manufacturing and business

\footnotetext{
"We combine "remanufact*" AND "simulat*" OR "modelling" on SCOPUS and it produced 56 articles, spread across journal articles (38) and conference papers (18). There was no limit put on the year of article publication. This search was done in November, 2019.
} 
undertaken in 2010, it was found out that system dynamics (SD), discrete event simulation (DES) and agent-based modelling (ABM), also known as agent based-simulation were the most widely used in operational research (OR) to model business challenges [5]. Other simulation modelling techniques exist in manufacturing. In their review paper investigating simulation in manufacturing, Jahangirian et al. [24] identifies 17 simulation techniques or tools utilised in manufacturing. These include, DES, SD and ABM, as well as interactive simulation, spreadsheet simulation, Petri-nets, Monte Carlo simulation, process mapping, parallel simulation, Microsoft applications, process mapping, etc. [24]. These tools were utilised across a varied number of manufacturing applications; these include resource allocation, scheduling, supply chain management, production planning and inventory control, purchasing and maintenance management, amongst others [49]. These applications are also found within remanufacturing operations for remanufacturers. Thus, we argue that simulation modelling in remanufacturing can adopt lessons from manufacturing.

Following this, a number of papers have studied simulation modelling as it relates to remanufacturing. Using system dynamics modelling investigated remanufacturing closed-loop supply chain dominated by third party [40]. Their studies show that a remanufacturing model dominated by the third party is more effective than the traditional remanufacturing cycle. Also, subsidy policies on recycling and remanufacturing in the case of automobile parts in China was analysed using system dynamics [59]. The effect of the interaction of customer behaviour on economic viability of remanufacturing was investigated using a hybrid modelling approach that employed system dynamics and agent-based model [42]. Dulman and Gupta [11] use DES to compare regular and sensor-embedded wind turbine systems. This complemented by monitoring key variables in both systems, such as maintenance cost, disassembly cost, inspection cost and EOL profit. Maintenance [also referred to as reconditioning], disassembly and inspection form key elements of the remanufacturing process as captured in Fig. 1. The statistical significance were analysed using pairwise t-tests. From the articles obtained on SCOPUS wherein simulation modelling was performed in remanufacturing, we find out that system dynamics was used more in comparison to DES and SD.

Simulation modelling has been suggested as a method needed to assess and improve remanufacturing processes and production systems. It involves the development and analysis of models that imitate the behavior of the system being analyzed [22]. According to Pegden et al., [10] a simulation model can be used primarily for the following three purposes:
a. Analysis of system behavior
b. Development of theories and/ or hypothesis based on observed behavior
c. Prediction of future behavior.

Simulation modelling methods (SD, DES and ABM) can be described by their modelling paradigms. Events that occur continuously, such as machine deterioration can be modelled using system dynamics. Events that occur in discontinuous time steps, for example the breakdown of a machine, can be modelled using DES. ABM however, is normally applied for state transitions of elements, for

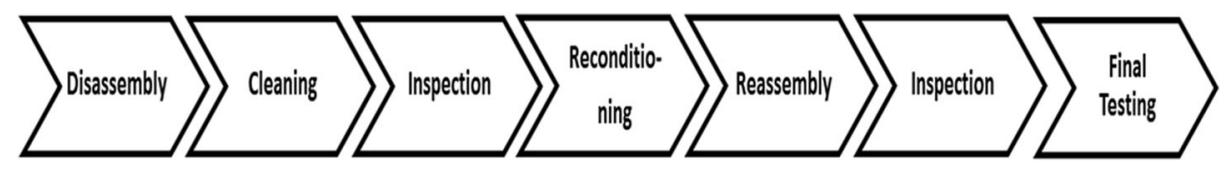

Fig. 1 A generic remanufacturing process chart based on the steps described in Steinhipher [53] 
example, a machine going from a state of working to a state of being idle. Thus, their deployment (also described as suitability or appropriateness and relevance) [24] in manufacturing have been argued to depend on levels of abstraction as indicated in Fig. 2.

While these three simulation modelling methods have been applied across diverse systems and processes, choosing one or a combination of these methods is dependent on the content of the system and the problem to be addressed as shown in Fig. 2. Ease and speed of building a simulation model also informs the choice of modelling for many researchers. From their investigation into the teaching of SD \& DES [19] found out that student modellers found it much easier to conceptualise material aspects of a system using DES than conceptualising the intangible properties of the same system using SD modelling. The ranking thus, will be in the form DES, SD and ABM. Their research also shows a clear trend in understanding DES modelling skills as compared to SD modelling skills [19]. A reason for this could be that students may not readily recognise feedback loops when they analyse SD simulation models, as linear thinking is a norm for novice modellers [29, 41].

\section{Challenges in smart remanufacturing operations: a simulation modelling solution?}

Increasingly pervasive in manufacturing is industry 4.0 adoption $[8,34,48]$. Industry 4.0 is the synonym for the transformation of today's factories into smart factories. The aim is to address and overcome the current manufacturing challenges of highly customised products, shorter product lifecycles and stiff global competition [61]. Traditional automation, for example, cannot achieve the degree of flexibility that is high product variability and shortened product-lifecycles demands.

Thus, as more OEMs digitalise and adopt Industry 4.0 tools, remanufacturing operations will also see the need for Industry 4.0 adoption as their cores come from these OEMs. Already, there have been opportunities identified in remanufacturing literature for the integration of Industry 4.0 and remanufacturing. These include the utilising of monitoring tools and robotics in smart lifecycle data

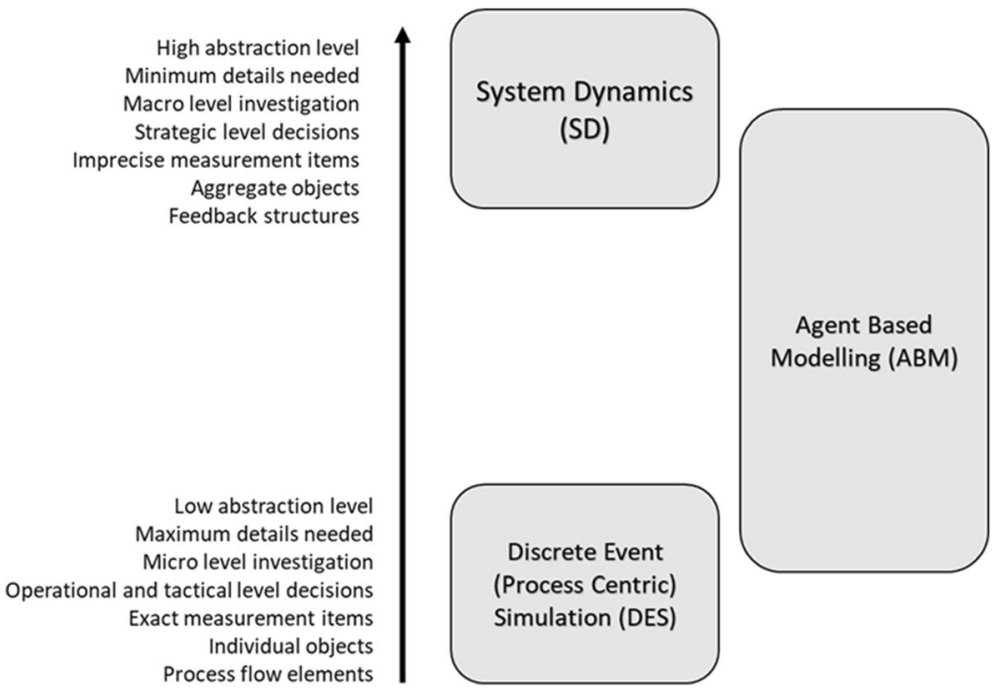

Fig. 2 Abstraction levels for the simulation modelling methods (adapted from Borshchev, [4]) 
for design for remanufacturing; smart sensors, additive manufacturing in order to build a smart remanufacturing factory [62] involving the various remanufacturing process in Fig. 1. With Industry 4.0 and digitalisation of remanufacturing systems comes data volume, variety and velocity [23, 33]. For remanufacturing, the entry of Industry 4.0 and subsequent data increase is expected to increase process complexity with more data produced as sensor-enabled products enter the remanufacturing shop-floor. Studies have shown that remanufacturing companies react passively to these complexity [6]. As remanufacturing is primarily driven by the relationship between the original equipment manufacturer (OEM) and the third party remanufacturer (TPR), the uptake of I4.0 by the OEM is expected to affect remanufacturing and slowly driving remanufacturing towards end-to-end digitalisation of the physical assets and the entire supply chain [31]. Butzer et al. [7] describes this as remanufacturing 4.0 .

This study advances its problem area from our previous study where we developed a framework to support a simulation-based understanding of digitalisation remanufacturing operations [46]. In that paper, we undertake a qualitative study using a sample of 5 manufacturing and remanufacturing companies. The study agrees with related studies [16, 62] which suggests that simulation modelling can actively enable Industry 4.0 adoption in remanufacturing. We however, advance a framework to support this adoption. This and the methodology for this paper is presented in the next section.

\section{Methodology}

In our previous study, we advance a framework to support a simulation-based understanding for digitalisation in remanufacturing, modelled according to the framework for hybrid simulation in Brailsford et al., [5]. This is presented in Fig. 3 below:

Following the framework in Fig. 3, we identify our remanufacturing problem, as highlighted in the first section of this study to be, "How simulation modelling using individual modelling tools support smart remanufacturing operations?" We examine smart remanufacturing operation by assessing a sensor-enabled product as it goes through the remanufacturing process as captured in Fig. 1. We assume that, due to the influence of I4.0 paradigms, the smart remanufacturing process in Fig. 1 will be much faster than what is obtainable in traditional remanufacturing. This assumption was modelled into the simulation. The remanufacturing operation is modelled and simulated using SD, DES and ABM and outputs such as remanufacturing cycle, are analysed. Assumptions required in the simulation model are agreed with remanufacturing experts as identified in [46]. These experts also provide qualitative validation for our simulation models.

This study builds on two earlier studies by the same author. In these studies, SD and DES were utilised in a remanufacturing set up $[22,36]$. Some of the results have been replicated in this study. Finally, we perform a cross-case analysis of the three simulation methods.

\section{Use case}

We use the remanufacturing process for an independent remanufacturer processing a rechargeable energy storage system (RESS) as a use case for the SD model. We have previously described the remanufacturing process of the RESS in two previously published papers [43-45]. We use an electric motor (rotor, an electrical component and a shaft, a mechanical component) to inform the use case for the DES and ABM model. 


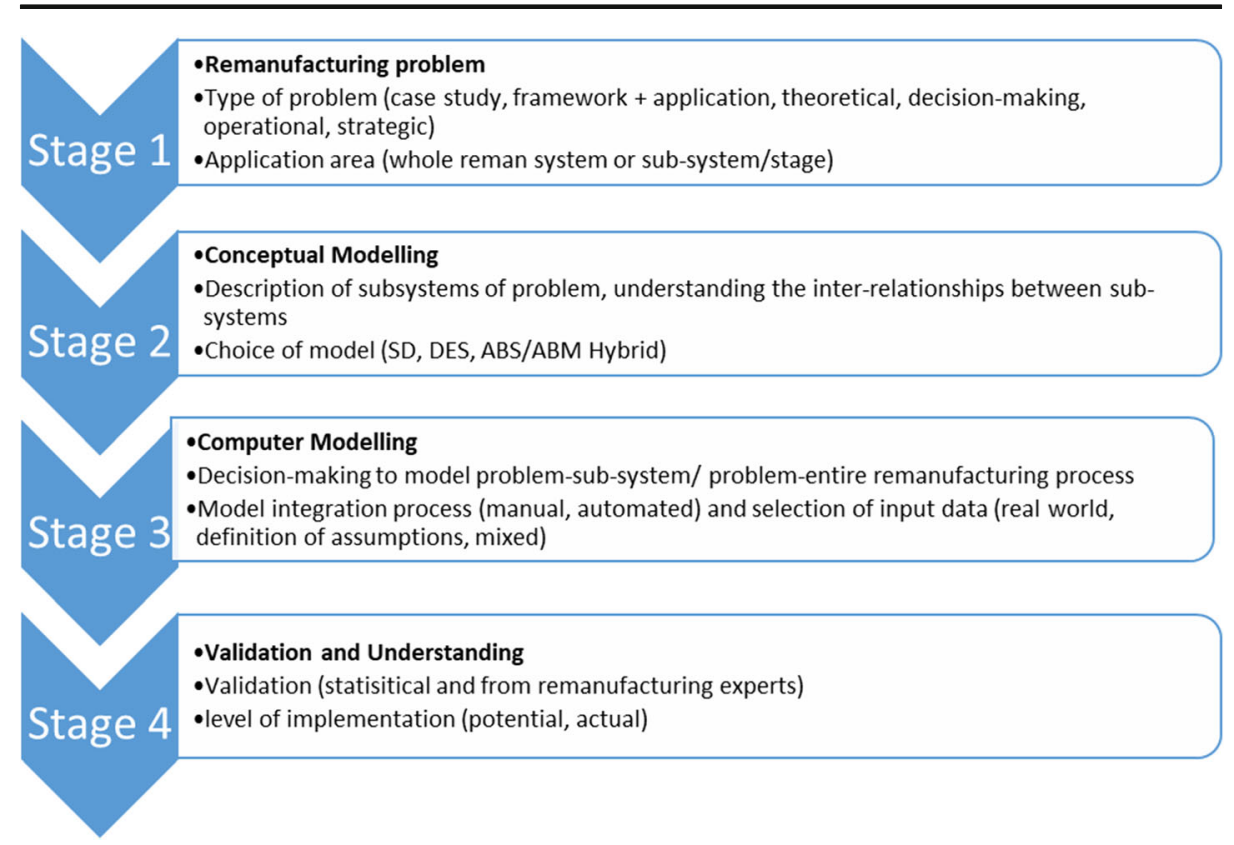

Fig. 3 Framework to support a simulation-based understanding of digitalisation in remanufacturing. (Source: Okorie et al., [46])

\section{Case 1: System dynamics (SD)}

Using SD modelling, we map out the structure of a remanufacturing system. First a Causal Loop Diagram (CLD) is developed as shown in Fig. 4. The CLD is used in representing the feedback structure of systems [54]. The CLD simply asks: what are the feedback processes responsible for the dynamics in the system? The remanufacturing operation is defined as a complex system, where in a CLD the case and effect connections often form loops which indicate information feedback between parameters. The behaviour and structure of the system is defined by the nature of these feedback loops.

The CLD is expressed as a mathematical model after the different interactions and feedback among the different variables of the elements are considered [45]. This is then converted to computer simulations or the Stock and Flow Diagram (SFD) [3]. Negative (-) and positive (+) polarities are assigned to the causal link on the CLD. The polarities represent the relationships between respective connected parameters. These polarities also indicate how a dependent parameter changes when an independent parameter changes [1]. The notation $\mathbf{B}$ and $\mathbf{R}$ signify a negative (or balancing) loop and a positive (or reinforcing) loop, respectively.

Assumptions are important in developing the CLD and the SFD. For this research question, we make two assumptions:

- The remanufacturing variables shall be analysed based on their process data and not the remanufacturing processes as described in Steinhilper [53].

- We assume remanufacturing a sensor-enabled product represent digitalised remanufacturing. 


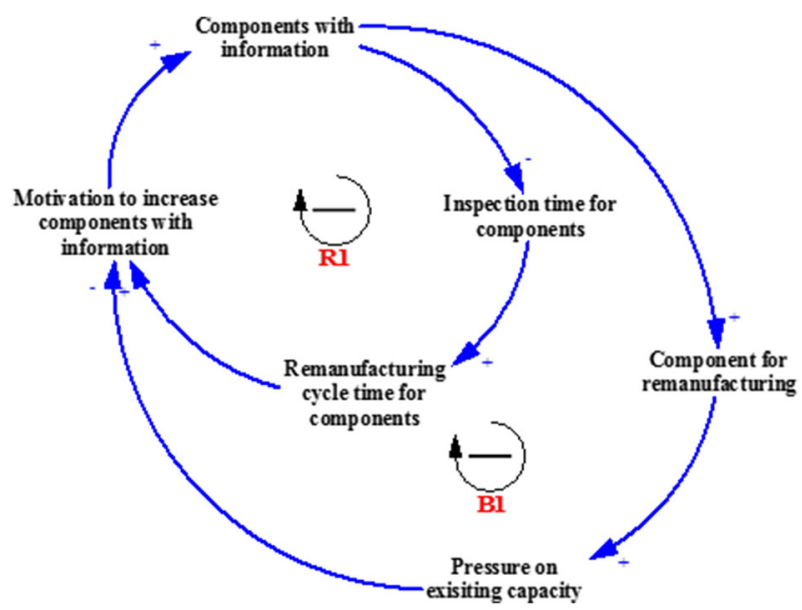

Fig. 4 CLD indicating the dynamic implications of component data on the remanufacturing system for the component. (Source: Okorie et al, [45])

- That, for simplicity's sake, these data shall be analysed as "data from sensors" (for example, vibration data and stack voltage, etc.) and "data from other sources" (for example, data from traditional remanufacturing parameters). This descriptions are given in paper published in Journal of Manufacturing and Materials Processing (Okorie et al., [45])

- That information about a component is required before the point of inspection and sorting in order for it to be remanufactured.

- That components with information do not require detailed inspection (hence just sorting, eliminating the inspection process) as their status is already known from the data. Components without information need to be inspected physically before it can be determined whether to remanufacture them or not.

From the developed CLD, it can be observed that when more components with data enter the remanufacturing line, the inspection time for components decrease which consequently reduces the overall remanufacturing cycle time. When cycle time decreases, management is motivated to further increase the components with information, seeing it as a benefit to be reinforced, R1. As components with information increases, the number of components entering the reman stream increases. This increase exerts pressure on existing capacity, hence encouraging management to reduce the components with information so as not to overload the system, represented in Fig. 4 as B1. Both feedback loops are in conflict. The CLD representing the two key feedback loops is shown in Fig. 4. We proceed to draw the SFD based on the CLD. Figure 5 expands the CLD into an SFD.

Accordingly the SFD is used to increase the understanding of the feedback and control process of a given system [3]. The intended simulation model can be used to test various policies regarding whether the company should increase data about the components to remanufacture, on the assumption that the increased availability of information about the component means that it is more likely the component can be sent for remanufacturing and vice versa. The less that is known about the component, the less likely it will be sent in for remanufacturing [45]. 


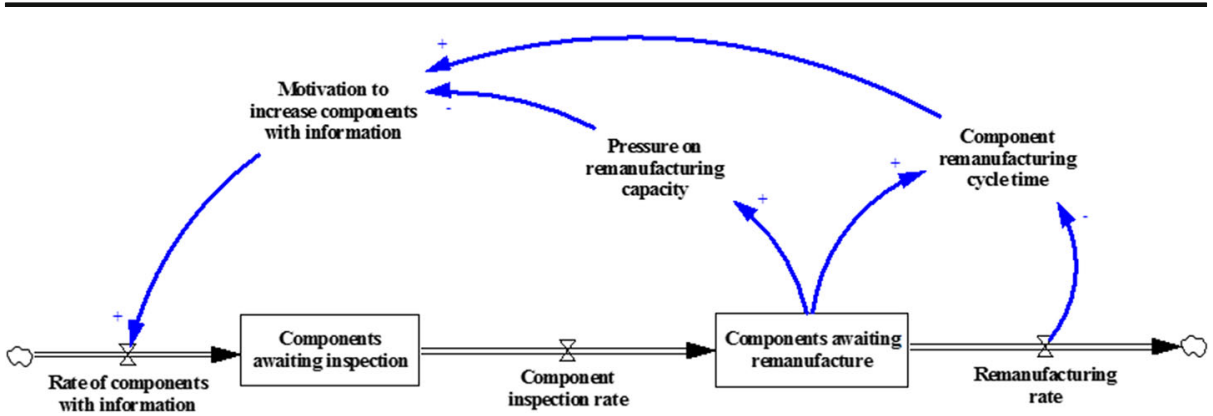

Fig. 5 SFD indicating the dynamic implications of component data on the remanufacturing system for the component. (Source: Okorie et al, [45])

\section{Coding the simulation model (SD)}

Hypothetical estimates are made to enable the presentation of simulation results that mirror how they may occur in real life. The below hypothetical estimates was used to code the SD and $\mathrm{ABM}$ simulation model and were validated by remanufacturing professionals (see: [45])

- Rate of entry of components to be remanufactured

- $\quad$ Random, between 1 and $3 \mathrm{~h}$ (SD)

- 1 in 12 min which equals 5 per hour. (ABM)

- Percentage of components with information $=5 \%$ (we take a pessimistic baseline situation, as if the majority of components have no information) (SD\&ABM)

- Percentage of components without information (it is assumed that some components without information are also entered into the system; those that are physically inspected)= 95\% (SD \&ABM)

- Inspection time per component (for those components with information)

- We use triangular distribution $(3,5,7)$ min. While a component may have data about it, it is important to still carry out some physical examination to confirm that it is fit for remanufacturing. This is akin to a verification inspection. We estimate a triangular distribution with $\min =3 \mathrm{~min}, \max =7 \mathrm{~min}$ and $\operatorname{mode}=5 \mathrm{~min}$. (SD)

- We use a uniform distribution $(5,10)$ minutes. While a component may have data about it, it is important to still carry out some physical examination to confirm that it is fit for remanufacturing. This is akin to a verification inspection. We estimate a triangular distribution with minimum $=5 \mathrm{~min}$, maximum $=10 \mathrm{~min}$. (ABM)

- Inspection time per component (for those components without information)

- Triangular distribution $(30,60,45) \mathrm{min}$ is used. We estimate a triangular distribution with $\min =30 \mathrm{~min} ; \max =60 \mathrm{~min}$ and $\operatorname{mode}=45 \mathrm{~min}$. (SD)

- Uniform distribution $(10,20)$ minutes is used. We estimate a triangular distribution with minimum $=10 \mathrm{~min}$; maximum $=20 \mathrm{~min}$. $(\mathbf{A B M})$ 
- Remanufacturing time per component

- Triangular $(2,3,5) \mathrm{h}$. We estimate a triangular distribution with $\min =2 \mathrm{~h}$, maximum $=$ $5 \mathrm{~h}$ and mode $=3 \mathrm{~h}$. (SD)

- Uniform distribution $(30,40)$ minutes. We estimate a minimum $=30$, maximum $=40$. (ABM)

- Remanufacturing capacity = we assume 1 set of machines. (SD\&ABM)

- Percentage of components (i.e., those without information) that are not remanufactured after inspection (since it is possible that some components will be found not to be "remanufacturable" after inspecting them physically) $=70 \%$. Hence, components that are remanufactured after they are physically inspected constitute $30 \%$ of the total. (SD)

\section{Sismulation results from System Dynamics}

Running the simulation model is expected to reveal how the system will behave (on the basis of the assumptions imputed) when the number of components with information is increased in the remanufacturing system. For an ideal situation, $100 \%$ of components will have information. In running the simulation model, two options are considered:

- We continue with the current capacity. Allow the components with information to vary such that capacity is not stretched. In such a situation, when capacity utilisation is approaching a high level (say, 80\%), the components with information are reduced, so as not to overburden the system. When there is slack, more components with information can be entered into the system.

- Ensure all components have information and determine (through simulation) the capacity that is needed to ensure that capacity is not overstretched or underutilised. Table 1 shows the SD simulation results when compared to current remanufacturing capacity status.

From the table above, the current capacity utilisation is low because there are not enough components entering the system (because there are not enough components with information). The system can be slightly improved by allowing the components with information to vary according to current available capacity. For an ideal situation, the capacity should be increased.

Table 1 Comparison of SD simulation results between real-time remanufacturing state and smart remanufacturing state

\begin{tabular}{llll}
\hline Quantities Monitored & $\begin{array}{l}\text { Current } \\
\text { Status }\end{array}$ & $\begin{array}{l}\text { Components with } \\
\text { Information are } \\
\text { Allowed } \\
\text { to Vary }\end{array}$ & $\begin{array}{l}\text { All Components have } \\
\text { Information and } \\
\text { Capacity } \\
\text { is Doubled }\end{array}$ \\
\hline $\begin{array}{l}\text { Average remanufacturing cycle time (min) } \\
\text { Number of remanufactured components }\end{array}$ & 306 & 350 & 225 \\
Average capacity utilisation & 1474 & 2096 & 4385 \\
\hline
\end{tabular}




\section{Case 2: Discrete event simulation (DES)}

DES is appropriate for understanding a hypothesized digital remanufacturing operations as it allowed the modellers to view the system as a sequence of operations focusing on the processes at a medium level of abstraction. Thus, DES allows for modelling and visualisation of complex manufacturing system without restrictions on the number of units.

In the development of DES model, the model was specified as a process flowchart where blocks represented various remanufacturing operations as specified in Fig. 1. However, we introduce two other processes; hence the entire process is detailed as: Collection, Inspection \& Sorting, Disassembly, Cleaning, Inspection \& Grading, Fault Diagnosis \& Prognosis, Reconditioning, Reassembly, Testing and Final Assembly. Key variables include to build the model include; collection rate of returned products, attrition rate, reuse rate of products, rate of controlled disposal, remanufacturing capacity, products accepted for reuse.

In order to give more insights to the model, the concept of certainty of product (CPQ) was developed. It improves the way in which value in remanufacturing is quantified based on the amount of data that is available to provide information about the returned product. CPQ is a function of the physical condition of the product (PC), part remanufacturing history (PRM), part replacement history (PRH) and the data from sensors (DS) and is defined by the equation below: 2

$$
C P Q=(w 1 * P C)+(w 2 * P R M)+(w 3 * P R H)+(w 4 * D S)
$$

Where $w 1, w 2, w 3, w 4$ are individual weights which are dependent on external factors such as the nature of the product, the nature of the industry, etc. The sum of weights $w 1, w 2, w 3, w 4$ is equal to 1 and PC, PRM, PRH and DS are normalised. The definition of the CPQ elements and weight is detailed in our earlier research [9]. Figure 6 gives a process flow chart for the DES model where key parameters at each stage are highlighted.

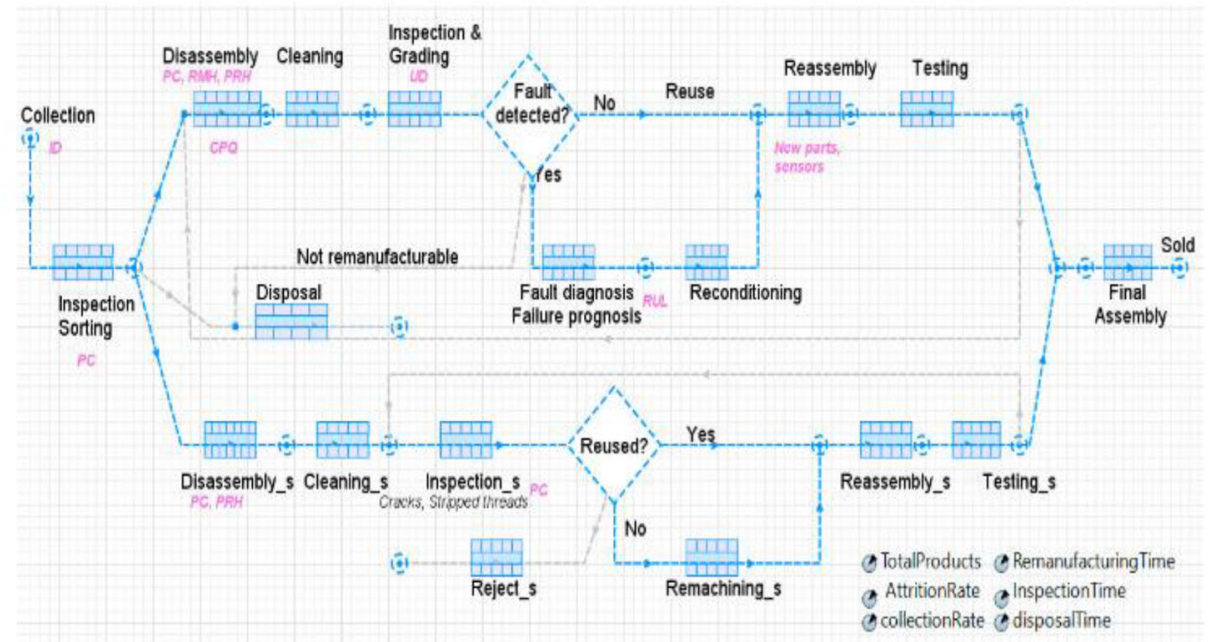

Fig. 6 Discrete Event Simulation (DES) showing key parameters at each stage. (Source: Charnley et al., [9]) 


\section{Coding the simulation model (DES)}

Similar to the SD and ABM model, we agree hypothetical estimates in order to code the simulation model. These include:

- Collection of returned products: The attrition rate for the electrical products was assumed to be $3 \%$ [60]. We assume the number of products in use to be 1000 .

- The rate of collection of cores is given by the equation below:

$$
\text { Collection rate }=\text { Total products } * \text { Attrition rate }
$$

- Inspection and sorting: The remanufacturing cores are collected and then inspected based on the physical condition (PC) of the core. The product identification number (ID) also informs this inspection and sorting. Sorting and disassembly is done across product type (electrical components and mechanical components). We estimate that $10 \%$ of the products are rejected and sent for disposal at this stage.

- Inspection and sorting time per component was a triangular distribution of $30 \mathrm{mins}, 60$ mins and 90 min respectively, with a minimum, maximum and mode of 30 mins, 60 mins and 90 mins are assumed.

- Disassembly: The CPQ of the returned product is determined and given a value of between 0.1 and 1 .

- Time taken for disassembly, cleaning and inspection: The understanding of remanufacturing process and the CPQ suggests that that the CPQ of the returned product will affect the disassembly time, cleaning time. A high CPQ value suggests that the remanufacturer does not need to go down to the lowest level of disassembly. This suggests that the CPQ of a product can be useful in predicting remanufacturing time and costs. Eqs. 3 to 5 attempts to quantify the CPQ in terms of time as thus:

$$
\begin{aligned}
& \text { Disassembly time }=\frac{\text { triangular }(0.5,1,1.5)}{C P Q} \\
& \text { Cleaning time }=\frac{\text { triangular }(0.5,1,1.5)}{C P Q} \\
& \text { Inspection time }=\frac{\text { triangular }(0.5,1,1.5)}{C P Q}
\end{aligned}
$$

- Inspection and grading: The condition and state of the component is measured during inspection (see Fig. 1). They are then separated into three sub-categories according to [53]; (a) directly reusable (b) reusable after sufficient repair or reconditioning is done and (c) cannot be repaired or reconditioned. Accordingly, "directly reusable" products are sent for reuse, "reusable after sufficient repair or reconditioning" are sent for fault diagnosis and failure prognosis (see Fig. 7) and "cannot be repaired or reconditioned" are sent for disposal as these cannot be remanufactured. 
- Fault diagnosis and prognosis: This is coded according to time for fault diagnosis and remaining useful life (RUL) for fault prognosis.

- Reconditioning and repair: Reconditioning and repair in remanufacturing are dependent on the state and the failure condition of the used parts. Here the PRM variable (see Eq. 1) is important in providing insights into the usefulness of reconditioning methods [9]

- Reassembly and testing: As seen in Fig. 7, the CPQ and time inform the information and variables needed for simulation at the final assembly.

- Final assembly: The simulation coding employed the first-in, first-out (FIFO) logic to control the other in which products were proceeded. This involves the final reassembly of the electrical and mechanical components before the product is sent back to market.

- Disposal: Products that cannot be remanufactured are sent for controlled disposal. We assume this to be a triangular distribution (time per component) of 60, 90 and $120 \mathrm{~min}$.

\section{Simulation output (DES)}

We present the simulation output around the CPQ concept. The model in Fig. 6 show the effect of CPQ on the time which is spent in disassembly, cleaning and inspection. Figure $8 \mathrm{a}, \mathrm{b}$ show a High CPQ (0.8 to 1$)$ and Low CPQ value (0.1 to 0.3$)$. For the model with high CPQ values,

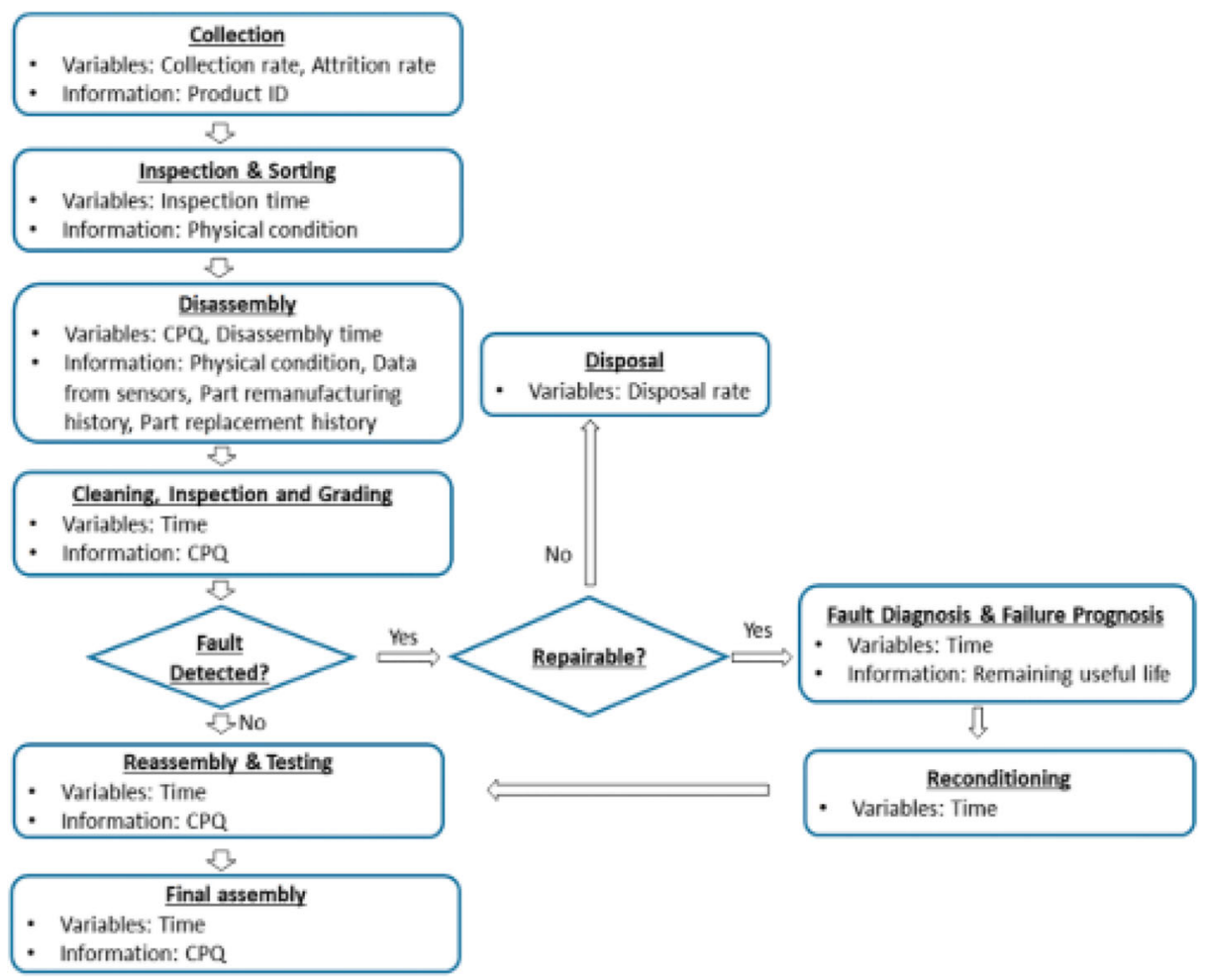

Fig. 7 A flowchart depicting the DES process, key variables and information required at each stage of remanufacturing. (Source: Charnley et al., [9]) 
$75 \%$ of the products spent $31-35 \mathrm{~h}$ in disassembly, cleaning and inspection with a mean value of $31 \mathrm{~h}$ when 100 products are remanufactured a shown in Fig. 8a. For the model with low CPQ values, $75 \%$ of the products spent $46-52 \mathrm{~h}$ in disassembly, cleaning and inspection with a mean value of $47 \mathrm{~h}$ as shown in Fig. 8b. The vertical dark blue line represents the mean value (Fig. 9).

An output of the DES model is the variations in the time spent in disassembly, cleaning and inspection for batches of high and low CPQ.

\section{Case 3: Agent based modelling (ABM)}

Agent-based models are detached and individual-centric method. The comprehensive behaviour emerges as a result of interactions of distinct individual behaviours. The main structure of agentbased models are state-charts. State-charts consist of states linked by transitions used to characterise the different status of an agent and their relationships. A state is the condition of an object in which it performs some activity or waits for an event. It represents different contexts in which system behaviours occur. A transition denotes a switch from one state to another. Transitions are relationships between states, drawn as arrows, optionally labelled by a trigger that causes actions.

In this agent-based remanufacturing model we assume each material behaves autonomously following the designed state-machine and random variables within the model. The statemachine (see Fig. 10) was built up based on the different process mode an actual remanufacturing system facilitates. The approach utilised in creating this model include; firstly, the active entities or agents (i.e., materials) and their environment (Remanufacturing system), was identified from the studied theory. Secondly, the interaction between each remanufacturing process and materials (i.e., based on their conditions) within the remanufacturing system were defined. This was used to build the remanufacturing state-machine. Thirdly, the materials were placed in the remanufacturing system then the simulation is run.

\section{Simulation model assumptions}

Below data are all hypothetical estimates to enable the presentation of simulation results that mirror what may occur in real life. This hypothetical data was agreed upon with the

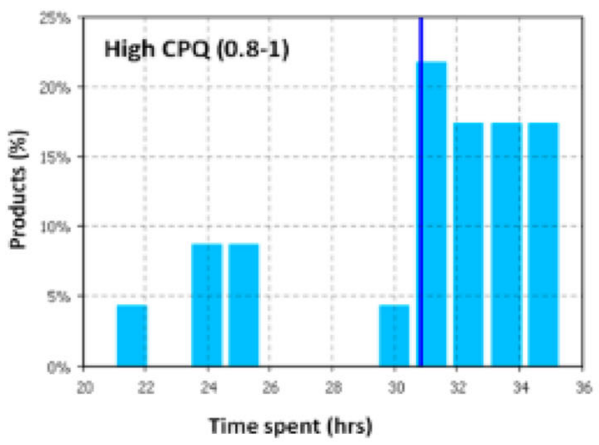

(a)

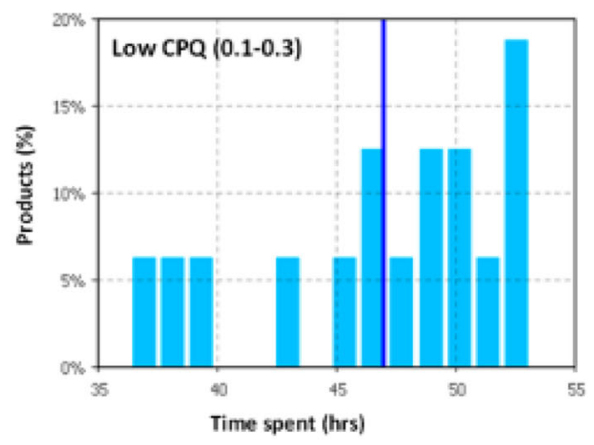

(b)

Fig. 8 Distribution of time spent in disassembly, cleaning and inspection for products with (a) high CPQ and (b) low CPQ. (Source: Charnley et al., [9]) 


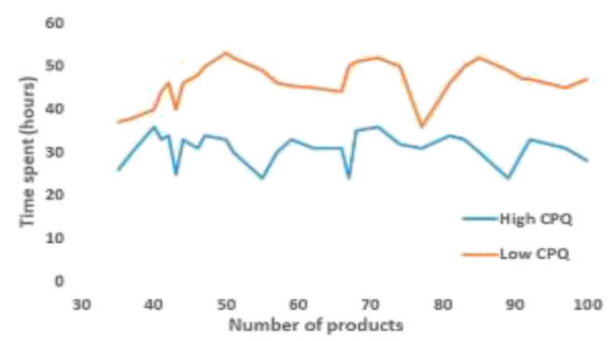

(a)

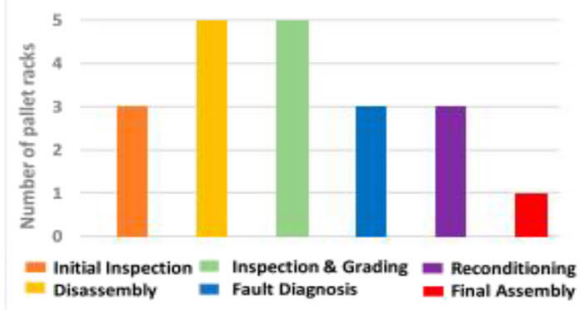

(b)

Fig. 9 a Time spent in disassembly, cleaning and inspection for a low and high CPQ in small number of products. b Maximum utilisation of pallet racks in different sections within a remanufacturing facility. (Source: Charnley et al., [9])

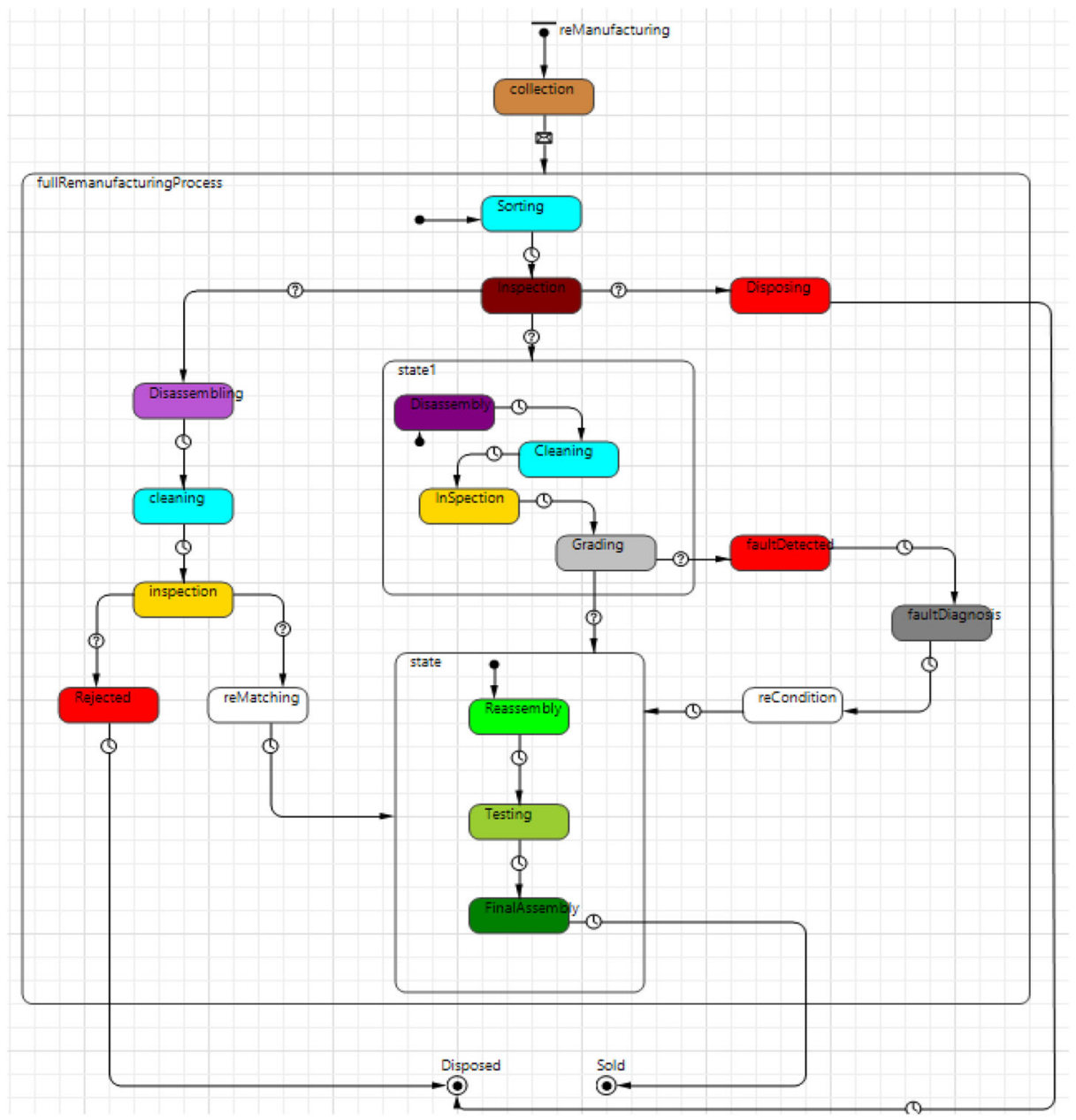

Fig. 10 Remanufacturing state-machine 
respondents; however, using more realistic data (real estimates from one of the companies) would be ideal.

Rate of entry of components to be remanufactured $=1$ in 12 min which equals 5 per hour.

Percentage of components with information $=5 \%$ (we take a pessimistic baseline situation, as if the majority of components have no information).

Percentage of components without information (it is assumed that some components without information is also entered into the system; those that are physically inspected) $=95 \%$.

Inspection time per component (for those components with information) $=$ We use a uniform distribution $(5,10)$ minutes. While a component may have data about it, it is important to still carry out some physical examination to confirm that it is fit for remanufacturing. This is akin to a verification inspection.

Sorting (for those components all component at arrival with or without information): Uniform distribution $(10,20)$ minutes is used. We estimate a Uniform distribution with minimum $=10 \mathrm{~min}$; maximum $=20 \mathrm{~min}$.

Reconditioning time per component: Uniform distribution $(30,40)$ minutes. We estimate it with minimum $=30$, maximum $=40$.

Disassembly time: Uniform distribution $(10,20)$ minutes. We estimate it with minimum $=10$, maximum $=20$.

CPQ Value: Each material CPQ value was calculated following a uniform distribution between $(0,1)$, where material with CPQ values less than $10 \%$ are immediately disposed, greater than $10 \%$ but less than $40 \%$ are taking for re-inspection, and greater than $40 \%$ are sent into the remanufacturing process.

Re-Inspection (for materials with CPQ values below 40\%): Each material with CPQ values below $40 \%$ are re-inspected using uniform distribution between $(0,1)$, where materials with values less than $50 \%$ are disposed and the other (that is, greater than 50\%) are accepted.

Grading: Each remanufactured material are graded to identify any fault within the materials. The materials are graded using a uniform distribution $(0,1)$, where materials with graded value less than $40 \%$ are sent for fault diagnosis, and those above $40 \%$ are sent for reassembly. Also, based on the graded value materials are categories into the following group; High Confidence: 0.8 to 1.0, Medium Confidence: 0.6 to 0.7 , and Low Confidence/ Uncertainty: 0.1 to 0.5 .

Fault Diagnosis Duration: the fault diagnosis duration for each material with graded value less than $40 \%$ sent for fault diagnosis is conducted using a uniform distribution $(10,30)$ minutes. We estimate a with minimum $=10 \mathrm{~min}$, maximum $=30 \mathrm{~min}$.

\section{Outputs}

The simulation model was run for 1000 materials using the stated assumptions. The model outputs include the remanufacturing cycle time, average time for the different remanufacturing processes and the comparison between materials sold (remanufacture) and the materials or components disposed.

\section{Discussion}

We present the simulation output looking at the interaction of each process mode within the entire system. Table 2 reveals the model output for over 1000 samples using the highlighted parameters discussed above. Figure 11 shows the average remanufacturing cycle time for over 1000 materials, while Fig. 12a, b depicts the PDF diagram and average time for the all legends (a) 
Table 2 Model output for over a 1000 sample

\begin{tabular}{lll}
\hline Parameters & Values & Outputs over \\
& & 1000 samples \\
\hline CPQ & $\begin{array}{l}\text { Disposed }=<10 \% \\
\text { Re-Inspection }=>10 \% \text { but }<40 \% \\
\text { (Disposed }=<50 \% ; \text { Accepted }=>50 \%)\end{array}$ & $\begin{array}{l}\text { Disposed }=20 \% \text { of Samples } \\
\text { Accepted }=80 \% \text { of Samples }\end{array}$ \\
Disassembly Time & Accepted $=>40 \%$ & Average Time $=19.93 \mathrm{~min}$ \\
Sorting Time & Uniform distribution(10,20) Minutes & Average Time $=15.05 \mathrm{~min}$ \\
Inspection Time & Uniform distribution(10,20) Minutes & Average Time $=7.56 \mathrm{~min}$ \\
Reconditioning Time & Uniform distribution(5,10) Minutes & Average Time $=35.37 \mathrm{~min}$ \\
Fault Diagnosis Time & Uniform distribution(30,40) Minutes & Average Time $=17.17 \mathrm{~min}$ \\
Cycle Time & Uniform distribution(10,25) Minutes & Average Time $=144.32 \mathrm{~min}$ \\
\hline
\end{tabular}

and CDF diagram and average time (b). The result shows that less than $10 \%$ of all samples were disposed either having a CPQ value less than $<10 \%$ when they were collected or $<50 \%$ when during re-inspection. From the model output, it takes an average time of $15.05 \mathrm{~min}$ to sort and inspect material after collection, while it takes an average of about $7.56 \mathrm{~min}$ to re-inspect a material. The Disassembly period takes an average of $19.93 \mathrm{~min}$ to complete and an average of $17.17 \mathrm{~min}$ for fault diagnosis. However, it takes an average of 35.37 min to recondition a material, resulting in an average duration of $144 \mathrm{~min}$ and over for a complete remanufacturing cycle.

Figure 13 shows the material grading based on the fault identified within the materials following the defined grading group; High Confidence: 0.8 to 1.0, Medium Confidence: 0.6 to 0.7, and Low Confidence/ Uncertainty: 0.1 to 0.5 . The result shows that about $45 \%$ sample were graded as low confidence material, $35 \%$ were graded as high confidence material, while $15 \%$ were graded as medium confidence material. This is indicated in Fig. 14.

\section{Summary}

An agent-based approach is flexible and easily extendible to greater detail. The approach has the potential to capture the rich and diverse behaviour of the remanufacturing industry. The
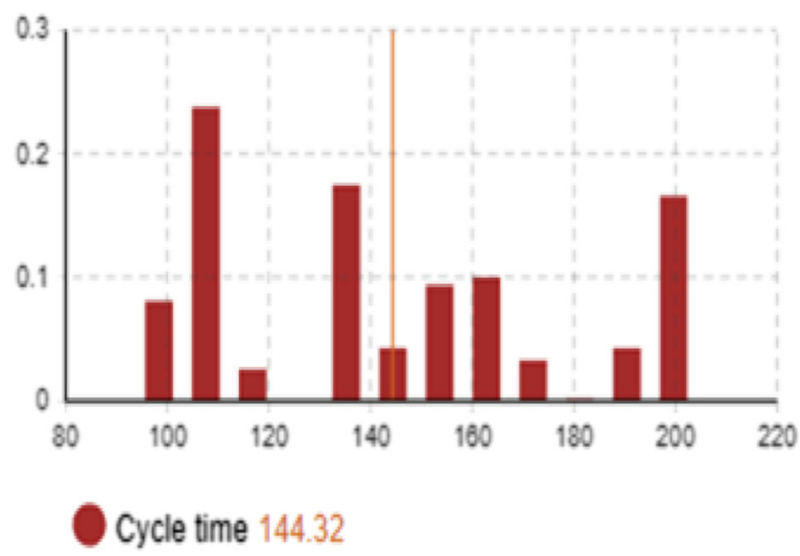

Fig. 11 Average remanufacturing cycle time for over 100 materials 


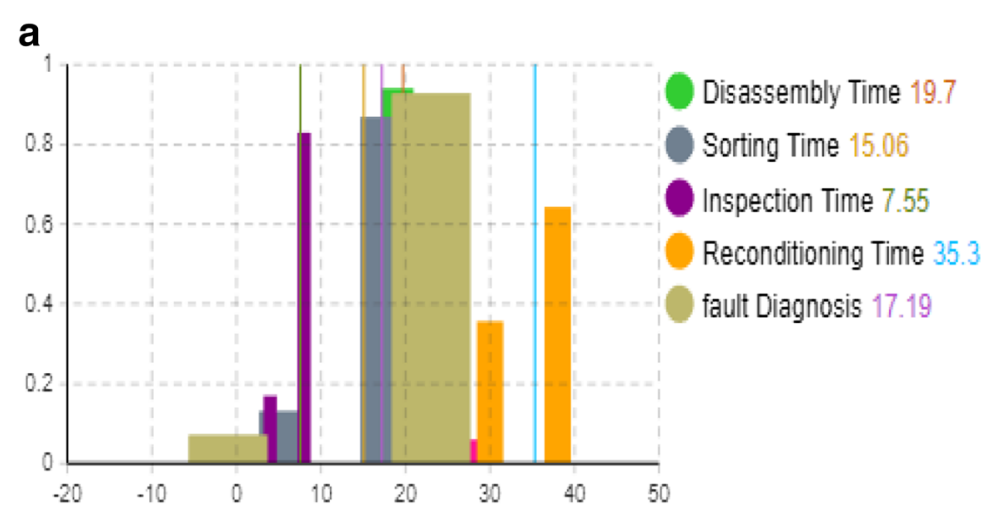

\section{b}

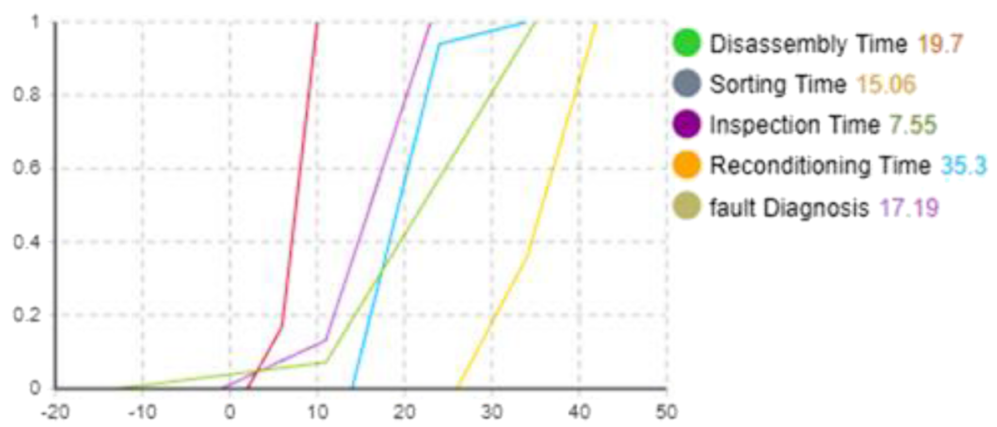

Fig. 12 a CDF diagram and average time for all the legends. b CDF diagram and average time

behavioural state-machine helps represent complex process and support integration of highlevel interaction at different stages in the remanufacturing process.

The emphasis of this section is on the proposed methodology for simulating and investigating the application of simulation modelling processes in the remanufacturing industry. The results presented are primary serve to demonstrate the ability within the modelling methodology to achieve a more realistic model and detailed result especially at micro level within the remanufacturing system.

\section{Cross-case analysis}

Analysing the three simulation modelling methods becomes possible as all three SM methods focuses on understanding how a digitised remanufacturing operation have with understood conditions. Major differences lies in the assumptions made in defining the models: While the CPQ concept was introduced for the DES and ABM model, the SD model relied on remanufacturing assumptions developed in building the CLD. This cross-case analysis shall examine the suitability and relevance of these simulation techniques to remanufacturing operation applications [24] by focusing on the assumptions and the outputs of individual SM.

Borshchev argues that SD modelling requires a high level of abstraction with minimum details required from the remanufacturing operators [4]. Thus in modelling the SD model we hypothesise assumptions based around data and data flow which we assume to be the main 


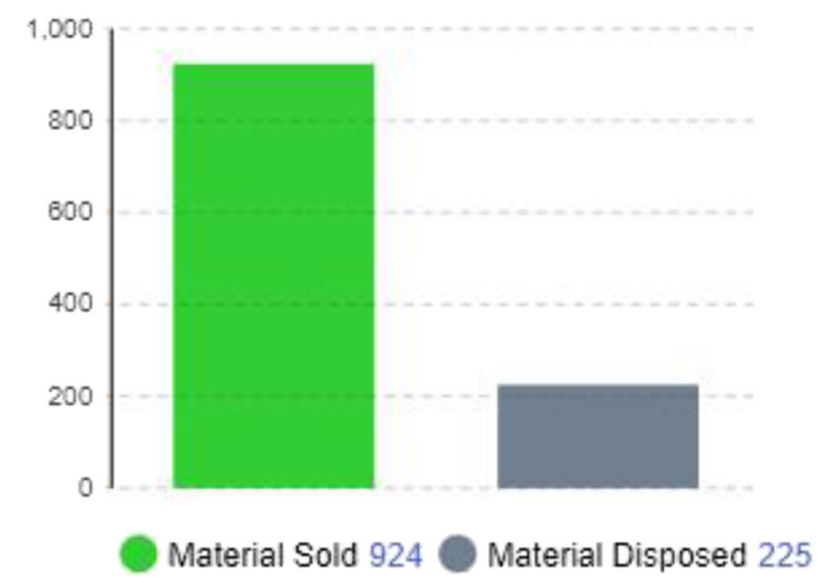

Fig. 13 Comparison between materials sold and disposed

difference when sensor-enabled products are remanufactured in comparison to non-sensor enabled products. While data and data flow is of significance to DES modelling, the microlevel investigation and process flow elements considerations which DES requires [4]. Thus this process flow elements are demonstrated in Figs. 6 and 7 where the sequence of remanufacturing from collection and inspection to final assembly is considered. For example, the DES model in Fig. 9 show that storage/workspace was allocated for each station in the form of pallet racks, hence determining the optimum resources needed to meet the product demand can be analysed from the DES model. The ABM model present similar results to the DES model but also identifies the average time required for disassembly, sorting, inspection, reconditioning and fault diagnosis in Fig. 11 when 1000 materials are put through the remanufacturing line. Knowledge of the time allocation can help the remanufacturers in strategic decision making which influences the human resources as well as the equipment utilised for remanufacturing (Table 3).

According to Katsaliaki \& Mustafee, ABM is a computational technique which is employed for modelling the actions and interactions of autonomous individuals (agents) in a network [26]. With ABM the focus is to assess the effects of the agents on the remanufacturing systems system and not to assess the effect of individual agents on the remanufacturing system. This results in output such as the grading state of the material that come through for remanufacturing. An ABM of 1000 materials, we expect a substantial number of the materials

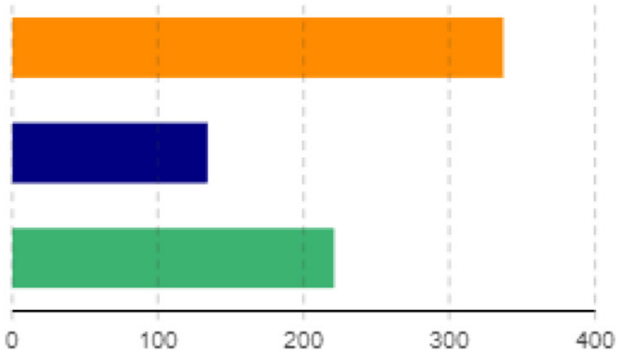

Low Confidence 337

Medium Confidence 134

High Confidence 221

Fig. 14 Confidence Level based graded value diagram 


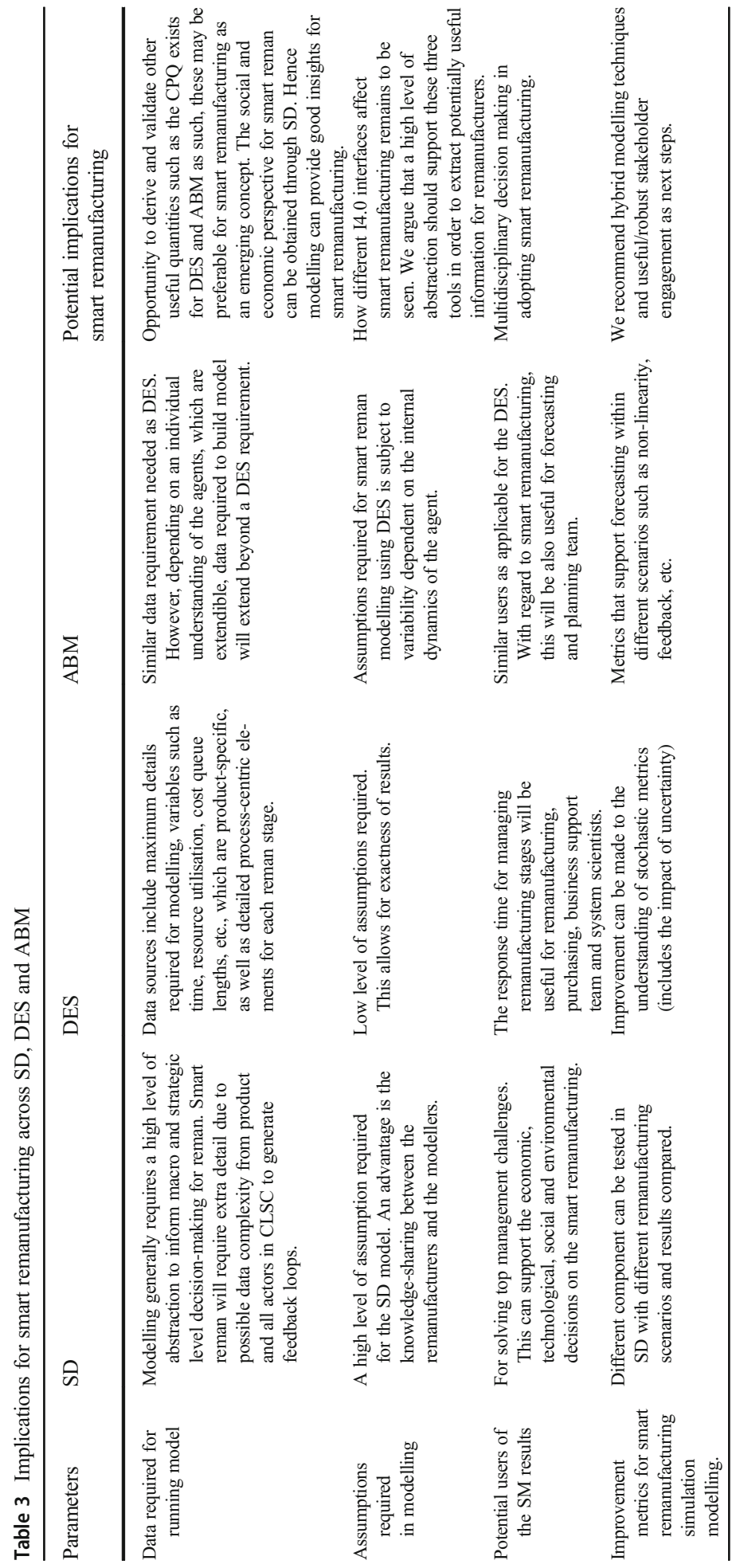


to have a high confidence CPQ value of between 0.8 to 1.0. As ABM has the capability of generating complex properties that emerge from the network of interactions among the agents, the CPQ concept alone may be limited in providing a high network of interactions within remanufacturing operations.

\section{Conclusions and future work}

Remanufacturing has a strategic importance as a value-retention process for industry and practitioners seeking to retain substantially greater inherent value in the system. This is asides the social, environmental and economic benefits that remanufacturing possesses. Overall, in the transition to a more circular economy, remanufacturing has been seen to create net-positive outcomes for circular economy through enabling product-level efficiency gains in material and energy use as well as in emissions and waste generation. As remanufacturing practices gains more attention globally, interest and research has also focused on the behaviour of digital technologies within the remanufacturing operations. Simulation modelling of remanufacturing operations has been suggested as a way of gaining insights of remanufacturing operations with digital interventions.

Using SD, DES and ABM and drawing from previous studies as published by the authors, we conduct a simulation modelling for a remanufacturable product as processed through a remanufacturing line. The SD modelling is developed based on assumptions driven by data while the DES and ABM assumptions is largely focused on data from product as well as the certainty of product quality concept, CPQ, which focuses on the way in which value in remanufacturing is quantified based on the amount of data that is available to provide information about the returned product. By running the simulation model as well as reviewing relevant literature, we make a number of conclusions. Firstly, we conclude that while individual modelling techniques can offer insights to these products, there are a lot of similarities with these insights, especially between DES and ABM modelling. Secondly, we conclude that product will a lot of data entering the remanufacturing process line offers insights into remanufacturing without negatively impacting the remanufacturing cycle. Thirdly, we conclude that the complexity in remanufacturing operations may require hybrid modelling, which are iteratively applied, in order to sufficiently understanding how remanufacturing operations behave in a digitised system. This can be a research area for future work. A much wider area for future research can be based on the understanding of hybrid modelling in remanufacturing and manufacturing operations through a systematic review of literature. This can offer insights into the assumptions needed by modellers in building a simulation model for remanufacturing.

Acknowledgements This research was supported by the Engineering and Physical Sciences Research Council No. EP/R032041/1. One of our co-authors, DT would like to acknowledge the support of Engineering and Physical Sciences Research Council of the UK through the Future Electrical Machines Manufacturing Hub (EP/S018034/1).

Open Access This article is licensed under a Creative Commons Attribution 4.0 International License, which permits use, sharing, adaptation, distribution and reproduction in any medium or format, as long as you give appropriate credit to the original author(s) and the source, provide a link to the Creative Commons licence, and indicate if changes were made. The images or other third party material in this article are included in the article's Creative Commons licence, unless indicated otherwise in a credit line to the material. If material is not included in the article's Creative Commons licence and your intended use is not permitted by statutory regulation or exceeds the permitted use, you will need to obtain permission directly from the copyright holder. To view a copy of this licence, visit http://creativecommons.org/licenses/by/4.0/. 


\section{References}

1. Adane T, Nicolescu M (2018) Towards a generic framework for the performance evaluation of manufacturing strategy: an innovative approach. J Manuf Mater Process 2(2):23. https://doi.org/10.3390/jmmp2020023

2. Amezquita T, Hammond R, Salazar M, Bras B (1995). Characterizing the Remanufacturability of engineering systems. Proceedings of ASME Advances in Design Automation Conference, DE-Vol. 82, September 17-20, (1993), 271-278. https://doi.org/10.1016/j.jaapos.2011.05.024

3. Asif FMA, Rashid A, Bianchi C, Nicolescu CM (2015) Resources, conservation and recycling system dynamics models for decision making in product multiple lifecycles. 101, 20-33

4. Borshchev, A. (2013). The big book of simulation modeling: Multimethod modeling with Anylogic 6. Anylogic North America.

5. Brailsford SC, Eldabi T, Kunc M, Mustafee N, Osorio AF (2018) Hybrid simulation modelling in operational research: a state-of-the-art review. Eur J Oper Res 278:721-737. https://doi.org/10.1016/j.ejor.2018.10.025

6. Butzer S, Kemnitzer J, Kunz S, Pietzonka M, Steinhilper R (2017a) Modular simulation model for remanufacturing operations. Procedia CIRP 62:170-174. https://doi.org/10.1016/j.procir.2016.06.012

7. Butzer S, Kemp D, Steinhilper R, Schötz S (2017b) Identification of approaches for remanufacturing 4.0. 2016 IEEE European Technology and Engineering Management Summit, E-TEMS 2016. https://doi. org/10.1109/E-TEMS.2016.7912603

8. Cezarino LO, Liboni LB, Oliveira Stefanelli N, Oliveira BG, Stocco LC (2019) Diving into emerging economies bottleneck: industry 4.0 and implications for circular economy. Manag Decis. https://doi. org/10.1108/MD-10-2018-1084

9. Charnley F, Tiwari D, Hutabarat W, Moreno M, Okorie O, Tiwari A (2019) Simulation to enable a datadriven circular economy. Sustainability 11(12):3379. https://doi.org/10.3390/su11123379

10. Dennis Pegden C, Shannon RE, Sadowski RP (1995) Introduction to simulation using SIMAN, 2nd edn. McGraw Hill, New York

11. Dulman MT, Gupta SM (2018) Maintenance and remanufacturing strategy: using sensors to predict the status of wind turbines. J Remanuf 8(3):131-152. https://doi.org/10.1007/s13243-018-0050-1

12. Ellen MacArthur Foundation. (2013). Towards the circular economy: Economic and business rationale for an accelerated transition (Vol. 2). https://doi.org/10.1007/b116400

13. Fakhimi M, Mustafee N, Stergioulas LK (2016) An investigation into modeling and simulation approaches for sustainable operations management. Simulation 92(10):907-919. https://doi.org/10.1177 /0037549716662533

14. Genovese A, Acquaye AA, Figueroa A, Koh SCL (2015) Sustainable supply chain management and the transition towards a circular economy: evidence and some applications. Omega. 66:344-357. https://doi. org/10.1016/j.omega.2015.05.015

15. Ghobakhloo M (2020) Determinants of information and digital technology implementation for smart manufacturing. Int J Prod Res 58(8):2384-2405. https://doi.org/10.1080/00207543.2019.1630775

16. Goodall P, Sharpe R, West A (2019) A data-driven simulation to support remanufacturing operations. Comput Ind 105:48-60. https://doi.org/10.1016/j.compind.2018.11.001

17. Guide VDR, Harrison TP, Van Wassenhove LN (2003) The challenge of closed-loop supply chains. Interfaces 33(6):2-6

18. Gunasekara H, Gamage J, Punchihewa H (2019) Remanufacture for sustainability: a review of the barriers and the solutions to promote remanufacturing. 2018 International Conference on Production and Operations Management Society, POMS 2018, (February 2019), 1-7. https:.1109/POMS.2018.8629474

19. Hoad K, Kunc M (2018) Teaching system dynamics and discrete event simulation together: a case study. J Oper Res Soc 69(4):517-527. https://doi.org/10.1057/s41274-017-0234-3

20. Holgado M, Aminoff A (2019) Closed-loop supply chains in circular economy business models. In: Ball P, Huaccho Huatuco L, Howlett RJ, Setchi R (eds) Sustainable design and manufacturing 2019. Springer Singapore, Singapore, pp 203-213

21. Ijomah WL, Bennett JP, Pearce J (1999) Remanufacturing: evidence of environmentally conscious business practice in the UK. Proceedings - 1st International Symposium on Environmentally Conscious Design and Inverse Manufacturing, EcoDesign 1999, 192-196. https://doi.org/10.1109/ECODIM.1999.747607

22. Ilgin AM, Gupta SM (2012) Remanufacturing modelling and analysis, 1st edn. CRC Press, Boca Raton

23. Intel Corporation (2014) Optimizing manufacturing with the internet of things. In Intel Corporation. Retrieved from http:/www.intel.com/content/www/us/en/internet-of-things/white-papers/industrialoptimizing-manufacturing-with-iot-paper.html https://doi.org/10.1016/j.promfg.2020.02.146. Accessed 25 Jan 2020

24. Jahangirian M, Eldabi T, Naseer A, Stergioulas LK, Young T (2010) Simulation in manufacturing and business: a review. Eur J Oper Res 203(1):1-13. https://doi.org/10.1016/j.ejor.2009.06.004 
25. Kang HS, Lee JY, Choi S, Kim H, Park JH, Son JY, Kim BH, Noh SD (2016) Smart manufacturing: past research, present findings, and future directions. Int J Precis Eng Manuf - Green Technol 3(1):111-128. https://doi.org/10.1007/s40684-016-0015-5

26. Katsaliaki K, Mustafee N (2011) Applications of simulation within the healthcare context. J Oper Res Soc 62(8):1431-1451. https://doi.org/10.1057/jors.2010.20

27. Kerin M, Pham DT (2019a) A review of emerging industry 4.0 technologies in remanufacturing. J Clean Prod 237:117805. https://doi.org/10.1016/j.jclepro.2019.117805

28. Kerin M, Pham DT (2019b) Smart remanufacturing : a review and research framework. https://doi. org/10.1108/JMTM-06-2019-0205

29. Kunc M (2006) Teaching strategic thinking using system dynamics:lessons from a strategic development course. Syst Dyn Rev 22(22):2006. https://doi.org/10.1002/sdr

30. Kurilova-Palisaitiene J, Sundin E (2014) Challenges and opportunities of lean remanufacturing. Int J Autom Technol 8(5):644-652. https://doi.org/10.20965/ijat.2014.p0644

31. Kurilova-palisaitiene J, Lindkvist L, Sundin E (2015) Towards facilitating circular product life-cycle information flow via remanufacturing. Procedia CIRP 29:780-785. https://doi.org/10.1016/j. procir.2015.02.162

32. Kurilova-Palisaitiene J, Sundin E, Poksinska B (2018) Remanufacturing challenges and possible lean improvements. J Clean Prod 172:3225-3236. https://doi.org/10.1016/j.jclepro.2017.11.023

33. Laney D (2001) META Delta. https://doi.org/10.1016/j.infsof.2008.09.005

34. Lasi H, Fettke P, Kemper HG, Feld T, Hoffmann M (2014) Industry 4.0. Bus Inf Syst Eng 6(4):239-242

35. Lee S, Kwak M (2018) A review of the research on remanufacturing using the citation network analysis. ICIC Express Lett 12(4):345-351. Retrieved from https:/www.researchgate.net/requests/r51557416. Accessed 25 Jan 2020

36. Lund RT (1996) The remanufacturing industry: hidden giant. In Journal of Industrial Ecology. Retrieved from https://jie.yale.edu/remanufacturing-industry-hidden-giant. Accessed 25 Jan 2020

37. Lund RT, Mundial B (1984) Remanufacturing: The experience of the United States and implications for developing countries. (31), 126. Retrieved from http://documents.worldbank.org/curated/en/792491468142480141 /Remanufacturing-the-experience-of-the-United-States-and-implications-for-developing-countries. Accessed 25 Jan 2020

38. MacArthur E (2013) Towards the circular economy: a opportunities for the consumer goods sector. In Ellen MacArthur Foundation: Towards the Circular Economy (Vol. 10). https://doi.org/10.1162 /108819806775545321

39. Merchant ME (1994) Manufacturing in the 21st century. J Mater Process Technol 44:145-155

40. Miao S, Wang T, Chen D (2017) System dynamics research of remanufacturing closed-loop supply chain dominated by the third party. Waste Manag Res 35(4):379-386. https://doi.org/10.1177/0734242X16684384

41. Morgan J, Howick S, Belton V (2011) Designs for the complementary use of system dynamics and discreteevent simulation. Proceedings - Winter Simulation Conference, 2710-2722. https://doi.org/10.1109 /WSC.2011.6147977

42. Nassehi A, Colledani M (2018) A multi-method simulation approach for evaluating the effect of the interaction of customer behaviour and enterprise strategy on economic viability of remanufacturing. CIRP Ann 67(1):33-36. https://doi.org/10.1016/j.cirp.2018.04.016

43. Okorie O, Turner C, Salonitis K, Charnley F, Moreno M, Tiwari A, Hutabarat W (2018a) A decisionmaking framework for the implementation of remanufacturing in rechargeable energy storage system in hybrid and electric vehicles. Procedia Manuf 25:142-153. https://doi.org/10.1016/j.promfg.2018.06.068

44. Okorie O, Salonitis K, Charnley F, Moreno M, Turner C, Tiwari A (2018b) Digitisation and the circular economy: a review of current research and future trends. Energies 11(11):3009. https://doi.org/10.3390/en11113009

45. Okorie O, Salonitis K, Charnley F, Turner C (2018c) A systems dynamics enabled real-time efficiency for fuel cell data-driven remanufacturing. J Manuf Mater Process 2(77). https://doi.org/10.3390/jmmp2040077

46. Okorie O, Charnley F, Salonitis K (2019) A framework to support a simulation-based understanding of digitalisation in remanufacturing operations. In U. of Strathclyde \& L. University (Eds.), International Conference on remanufacturing. Amsterdam: ICOR 2019

47. Ponte B, Naim MM, Syntetos AA (2019) The value of regulating returns for enhancing the dynamic behaviour of hybrid manufacturing-remanufacturing systems. Eur J Oper Res 278(2):629-645. https://doi. org/10.1016/j.ejor.2019.04.019

48. PWC. (2014). Industry 4.0 - Opportunities and challenges of the industrial internet (Vol. 13). Retrieved from https://www.pwc.nl/en/assets/documents/pwc-industrie-4-0.pdf. Accessed 25 Jan 2020

49. Shafer SM, Smunt TL (2004) Empirical simulation studies in operations management: context, trends, and research opportunities. J Oper Manag 22(4 SPEC. ISS):345-354. https://doi.org/10.1016/j.jom.2004.05.002

50. Shi W, Feng T, Jo Min K (2016) Remanufacturing decision and sustainability under product life cycle uncertainty. Eng Econ 61(3):223-243. https://doi.org/10.1080/0013791X.2014.986352 
51. Smith GM, Sampath S (2018) Sustainability of metal structures via spray-clad remanufacturing. Jom 70(4): 512-520. https://doi.org/10.1007/s11837-017-2676-0

52. Song, G.-W., Liu, Y., Huang, Y.-B., Yang, F., \& Zhang, X.-Y. (2010). The study of digital remanufacturing engineering for vehicle engines. In Beijing Ligong Daxue Xuebao/Transaction of Beijing Institute of Technology (Vol. 30). https://doi.org/10.2174/092986710793348545

53. Steinhilper, R., (1998). Remanufacturing: The ultimate form of recycling, by Stuttgart: Fraunhofer IRB Verlag, 1998, $108 \mathrm{pp}$

54. Sterman, J. D. (2000). Systems thinking and modeling for a complex world. In Management (Vol. 6). https://doi.org/10.1108/13673270210417646

55. Sundin, E., (2004). Product and process design for successful remanufacturing. PhD Dissertation. Linkoping University

56. Sundin E (2019) Circular economy and design for remanufacturing. In: Charter M (ed) Designing for the circular economy, 1st edn. Routledge, London and New York, pp 186-199

57. UNEP. (2018). REDEFINING VALUE: the manufacturing revolution. Remanufacturing, Refurbishment, Repair and Direct Reuse in the Circular Economy. Summary for Policy Makers

58. Van Loon P, Delagarde C, Van Wassenhove LN, \& Mihelič, A. (2017). Comparing leasing and buying white goods for the manufacturer and consumer. International Conference on Remanufacturing. Linkoping, Sweden

59. Wang Y, Chang X, Chen Z, Zhong Y, Fan T (2014) Impact of subsidy policies on recycling and remanufacturing using system dynamics methodology: a case of auto parts in China. J Clean Prod 74: 161-171. https://doi.org/10.1016/j.jclepro.2014.03.023

60. Warken Industrial and Social Ecology PTY LTD. (2012). Analysis of lead acid battery consumption, recycling and disposal in western Australia. Retrieved from http:/www.batteryrecycling.org.au/wp-content/uploads/2012/06 /120522-ABRI-Publication-Analysis-of-WA-LAB-Consumption-and-Recycling.pdf. Accessed 25 Jan 2020

61. Weyer S, Schmitt M, Ohmer M, Gorecky D (2015) Towards industry 4.0 - standardization as the crucial challenge for highly modular, multi-vendor production systems. IFAC-PapersOnLine 48(3):579-584. https://doi.org/10.1016/j.ifacol.2015.06.143

62. Yang, S., Aravind Raghavendra, M. R., , Kaminski, J., \& Pepin, H. (2018). Opportunities for industry 4.0 to support remanufacturing. Appl Sci, 8(7), 1177, https://doi.org/10.3390/app8071177

63. Zahoor S, Abdul-Kader W, Zain M (2019) The prospect of smart-remanufacturing in automotive SMEs: a case study. Proceedings of the International Conference on Industrial Engineering and Operations Management, 735-736

Publisher's note Springer Nature remains neutral with regard to jurisdictional claims in published maps and institutional affiliations.

\section{Affiliations}

\section{Okechukwu Okorie $^{1} \cdot$ Fiona Charnley ${ }^{1} \cdot$ Augustine Ehiagwina $^{2} \cdot$ Divya Tiwari $^{3}$. Konstantinos Salonitis ${ }^{4}$}

1 Exeter Centre for Circular Economy, Exeter Business School, Streatham Court, University of Exeter, Rennes Drive, Exeter EX4 4PU, UK

2 Liverpool Logistics Offshore and Marine Institute, Liverpool John Moores University, Brownlow Hill, Liverpool L3 5UG, UK

3 Department of Automatic Control and Systems Engineering, The University of Sheffield, Sheffield, UK

4 Sustainable Manufacturing Systems Centre, School of Aerospace, Transport and Manufacturing, Cranfield University, Bedford MK43 0AL, UK 